\title{
Predicting the unpredictable: How host specific is the mycobiota of bark and ambrosia beetles?
}

\author{
Kirsten E. Miller a, b, c, * , Daegan JG. Inward ${ }^{\mathrm{d}}$, Carola Gomez-Rodriguez ${ }^{\mathrm{e}}$, Andres Baselga ${ }^{\mathrm{e}}$, \\ Alfried P. Vogler ${ }^{\mathrm{a}, \mathrm{b}}$ \\ a Department of Life Sciences, Natural History Museum, Cromwell Road, London, SW7 5BD, UK \\ b Department of Life Sciences, Imperial College London, Silwood Park Campus, Ascot, SL5 7PY, UK

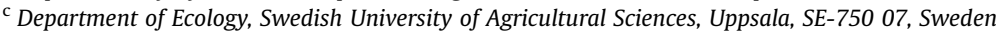 \\ d Centre for Ecosystems, Society and Biosecurity, Forest Research, Alice Holt Lodge, Farnham, Surrey, GU10 4LH, UK \\ e Departamento de Zoología, Facultad de Biología, Universidad de Santiago de Compostela, c/Lope Gómez de Marzoa s/n, 15782, Santiago de Compostela, \\ Spain
}

\section{A R T I C L E I N F O}

\section{Article history:}

Received 8 April 2019

Received in revised form

17 July 2019

Accepted 20 July 2019

Available online $\mathrm{xxx}$

Corresponding Editor: Nicolai Meyling

\section{Keywords:}

Mycobiota

Metabarcoding

Bark-beetles

Host-microbe interactions

\begin{abstract}
A B S T R A C T
Bark and ambrosia beetles (Curculionidae: Scolytinae) are known for their symbioses with fungi and play a key role in the dispersal of phytopathogens. The scolytine community of eight pine stands along a latitudinal gradient in the UK was surveyed and beetle-associated fungal communities (mycobiota) were assessed using ITS2 metabarcoding (304 specimens, 12 species). Distribution patterns among 2,257 detected fungal Operational Taxonomic Units (OTUs) revealed that beetle species identity was an important predictor of mycobiotic richness and composition, while the effects of environmental and spatial variables were negligible. Network-based specificity analysis suggested that a relatively small subset of OTUs ( 75 in total) exhibit an affinity for a subset of beetle species and that these include many Microascales and Saccharomycetes. Notably though, of the OTUs belonging to the family Ophiostomataceae, relatively few display host specificity. Our results add to the complex picture of host-associated fungal communities and suggest that host range limits are unlikely to restrict the spread of economically important phytopathogens.
\end{abstract}

Crown Copyright $\odot 2019$ Published by Elsevier Ltd. All rights reserved.

\section{Introduction}

Fungi display a diverse range of functional roles within forest ecosystems as decomposers, facilitators and phytopathogens. Some associations between fungi and trees are facilitated by interactions with bark and ambrosia beetles (Curculionidae: Scolytinae) (Paine et al., 1997; Six, 2012). While the majority of these beetle species feed upon dead or dying trees, some favour the phloem of living trees and, in partnership with their fungal symbionts, can overcome plant defenses (Brasier, 1991; Paine et al., 1997). The associations between bark and ambrosia beetles and fungi are usually multipartite, range from mutualistic to parasitic, obligate to facultative, and also comprise transient, nonsymbiotic associations (Six, 2012; Hulcr et al., 2015). Together,

\footnotetext{
* Corresponding author. Department of Ecology, Swedish University of Agricultural Sciences, Uppsala, SE-750007, Sweden.

E-mail address: kirsten.miller@slu.se (K.E. Miller).
}

these insect-fungus partnerships can shape forest ecosystems by facilitating wood degradation and increasing tree disease prevalence and mortality (Kirisits, 2004). As such, fungal-beetle systems can lead to the devastation of huge stands of trees and entire arboreal species at continental scales. The fungal order Ophiostomatales includes some of the most destructive species, for example the blue stain Grosmannia attacking various pine species in North America and Europe (Krokene and Solheim, 1998), the Ophiostoma novo-ulmi pathogen causing Dutch Elm Disease (Brasier, 1991), or the more recent outbreak of the laurel wilt Raffaelea vectored by Xyleborus glabratus in southeastern North America (Fraedrich et al., 2015). Each of these epidemics has had significant impacts through the loss of unique ecosystems and associated species, large-scale carbon release, and effects on local economies.

Due to their small size and ease of transport, bark and ambrosia beetles comprise a high proportion of alien invasive species; over 70 bark and ambrosia beetle species have been reported as invasive for North America and Europe alone (Haack, 2006; Kirkendall and 
Faccoli, 2010). In some cases, fungal phytopathogens are able to switch between beetle hosts upon entering a non-native range, forming a new association with a different beetle species. This was observed during the spread of the Dutch Elm Disease fungus, O. novo-ulmi and as a result of host switching, this fungus can be carried by 11 species of Scolytus, allowing its rapid dissemination throughout both North America and Europe in the 1960s (Brasier, 1991; Webber, 2000). Given the propensity of bark and ambrosia beetles to invade new ranges, host switching is of particular concern in this system. Indeed, a recent study found evidence of host switching between fungal symbionts that were previously believed to be highly specific and that phylogenetic distance is likely to influence the probability of this phenomenon occurring (Skelton et al., 2019). The degree to which beetle host identity governs fungal communities is essential knowledge for predicting host switching events as well as projecting range expansion and epidemic outbreaks.

In addition to the dependence on their scolytine hosts, fungal communities respond to other biotic, abiotic and spatial variables. Dead-wood associated fungi show significant tree species preferences (Purahong et al., 2018), and investigations into arbuscular mycorrhizal fungi suggest that temperature, sunshine hours (Dumbrell et al., 2011) and rainfall (Öpik et al., 2006; Hazard et al., 2013) all have a significant influence on community composition. Further, a recent large-scale global analysis of soil mycobiota revealed that climatic variables, particularly precipitation, were the dominant determinants of community composition (Tedersoo et al., 2014). The local environment is also likely to influence the mycobiota of insects, even if the effects may be constrained by symbiotic interactions.

Many studies investigating scolytine-fungus interactions have focused upon economically important beetles with a defined taxonomic and geographic focus, or those that can be cultured (Cassier et al., 1996; Hulcr et al., 2007; Cardoza et al., 2009; Endoh et al., 2011; Biedermann et al., 2012). While shedding light on potentially harmful pest species, this approach has left us with a somewhat limited perspective of the community level beetlefungal system, which has made it difficult to apply quantitative comparisons to separate drivers of these beetle mycobiota (Persson et al., 2009; Six, 2012).

Metabarcoding with fungal-specific ITS primers can assay fungal assemblages directly from the genomic DNA of an individual beetle or from the isolated mycangia, allowing rapid and relatively inexpensive molecular analysis of entire fungal communities associated with each specimen (Miller et al., 2016; Jacobsen et al., 2017; Malacrinò et al., 2017). Studies employing this approach have already revealed a much greater species diversity than expected from non-DNA based studies (Kostovcik et al., 2015; Miller et al., 2016). Here, we examine the mycobiota of bark and ambrosia beetles present in pine plantations along a north-south transect of the United Kingdom, to test for the partitioning of fungal communities within and between 12 scolytine species, in addition to the effects of biogeographic and environmental factors that may determine the turnover of fungal communities. The methodology permits the analysis of composition and host affinity for a large proportion of the fungal community, as well as a detailed study to examine which fungal taxonomic groups may be driving the community-level patterns. While it has been demonstrated that different beetle species display variation between their mycobiota, the relative importance of host identity and environmental conditions has not been previously explored in this system. We expect there to be an effect from each of these drivers and anticipate the variety of interactions as well as the diversity of fungal species to be reflected in the complexity of the communities uncovered.

\section{Methods}

\subsection{Study sites and collecting protocol}

Beetle specimens were collected from eight localities within UK Forestry Commission plantation forests during the summer of 2013 (Supplementary Data S1 and S2a). All sites comprised mature Corsican (Pinus nigra) and Scots pine (Pinus sylvestris) or a mix of the two, planted between 1952 and 1977 without recent thinning, and were selected to be typical of pine production forests across the UK. To reduce the incidence of non-pine specialists within catches, all trapping localities were within pine stands of at least 65 ha and were surrounded by other pine stands.

For each site, five receding Lindgren multiple-funnel traps (Pherotec, Victoria, Canada) were set up at $50 \mathrm{~m}$ intervals along a $250 \mathrm{~m}$ transect (see Supplementary Data S2b and S3 for details). Traps were baited with alpha-pinene and 100\% ethanol, both of which are effective attractants for saproxylic beetles (McIntosh et al., 2001). Ethanol was placed in collecting vials at the base of each trap, where it acted both as a lure and as a preservative for collected specimens. Traps were emptied once a week for 15 weeks between May and August. At each site all beetle specimens from all five traps were pooled together into fresh $100 \%$ ethanol and stored at $-20^{\circ} \mathrm{C}$ until processing.

\subsection{DNA extraction and sequencing}

Morphological identification of scolytines was conducted using standard identification keys (Duffy, 1953; Grüne, 1979) and confirmed using molecular sequence data. Specimens from the 12 most abundant beetle species were selected for mycobiome analysis. Between 6 and 70 individuals from between 4 and 8 sites (except Xylosandrus germanus from 1 site) were analysed from each species (Table 1 ).

To reduce the risk of cross-contamination between specimens within collection vials, we attempted to dislodge loose fungal spores by vortexing each beetle twice in fresh $70 \%$ ethanol for $30 \mathrm{~s}$. Since we were interested in the composition of the fungi attached to the cuticle of these specimens we did not surface sterilise, but to assess the level of cross-contamination we tested for an effect of the collection vial on the similarity of beetle mycobiota. PERMANOVA analysis suggested that there was no such effect (see Supplementary Data S4 for results) so while cross-contamination cannot be ruled out entirely, we are confident that the effect on our results and conclusions was negligible.

Prior to DNA extraction, the thorax of each beetle specimen was separated from the abdomen using sterilised forceps and both body parts were placed into a single well of a 96-well plate. One well of each plate was left empty as a negative control. DNA extractions were carried out for each beetle specimen individually using the Biosprint 96 Blood and Tissue extraction protocol (Qiagen, Valencia, CA). The ITS2 region was amplified using the fungus-specific, tagged primers ITS3 and ITS4 (White et al., 1990), which have low affinity for the corresponding locus in insects. Three separate PCRs were conducted for each specimen, each at a different annealing temperature $\left(50,53,56^{\circ} \mathrm{C}\right)$, and resulting amplicons were combined for sequencing (see Supplementary Data S5 for PCR cycling conditions). Extraction blanks and PCR blanks were used as negative controls. Library preparation was conducted separately on all amplicons corresponding to a single specimen using KAPA library kits (Kapa Biosystems), although the initial cleaning steps were modified to retain large DNA fragments and reduce amplicon loss. Sequencing was conducted on an Illumina MiSeq v. 3 ( 2 x 300 bps, paired-end) at the Natural History Museum Sequencing Facility. 
Table 1

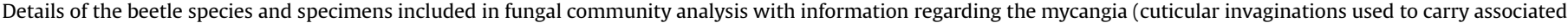
fungal spores and mycelia). possessed by each species.

\begin{tabular}{|c|c|c|c|c|}
\hline & Beetle Species & Description of Mycangial Structure & $\begin{array}{l}\text { Number of } \\
\text { specimens }\end{array}$ & $\begin{array}{l}\text { Number } \\
\text { of sites }\end{array}$ \\
\hline \multirow[t]{7}{*}{ Bark Beetles } & Hylastes ater & $\begin{array}{l}\text { Primative mycangia - secretion filled punctures in integument especially on the elytra, } \\
\text { both sexes (Kirisits, 2004) }\end{array}$ & 41 & 5 \\
\hline & Hylastes attenuatus & No known mycangia & 39 & 4 \\
\hline & Hylastes opacus & No known mycangia & 11 & 7 \\
\hline & Hylurgops palliatus & $\begin{array}{l}\text { Primative mycangia - secretion filled punctures in integument especially on the elytra, } \\
\text { both sexes (Kirisits, 2004) }\end{array}$ & 27 & 8 \\
\hline & Pityogenes bidentatus & No known mycangia & 11 & 7 \\
\hline & Pityophthorus pubescens & No known mycangia & 12 & 6 \\
\hline & Tomicus piniperda & No known mycangia & 51 & 8 \\
\hline \multirow[t]{5}{*}{ Ambrosia Beetles } & Trypodendron domesticum & Prothoracic-pleural mycangia (Batra, 1963) & 6 & 4 \\
\hline & Trypodendron lineatum & Prothoracic-pleural mycangia (Batra, 1963) & 12 & 6 \\
\hline & Anisandrus dispar & Prothoracic-pleural mycangia (Batra, 1963) & 39 & 5 \\
\hline & Xylosandrus germanus & Mesonotal mycangia (Hulcr et al., 2012) & 14 & 1 \\
\hline & Xyleborinus saxeseni & Elytral mycangia (Batra, 1963) & 41 & 6 \\
\hline
\end{tabular}

\subsection{Bioinformatic processing}

All libraries were quality checked using FastQC (Andrews, 2010) before merging with Fastq-join at a minimum similarity of 99\% > 50 bp (Aronesty, 2011). PRINSEQ-lite 0.20.4 (Schmieder and Edwards, 2011) was then used to remove reads with an average Q score of $<25$ and to trim bases below Q25 from 3' ends. No Ns were allowed, and only read lengths of over $>150$ bp were retained. Sequences were demultiplexed based on the unique tags and library indexes using Qiime's split_libraries.py script allowing for one-base mismatches (Caporaso et al., 2010). All sequences were then passed through the ITSx bioinformatics pipeline (Bengtsson-Palme et al., 2013) and only reads recognised as fungal ITS2 were retained. Operational taxonomic unit (OTU) clustering of ITS2 sequences was then done using the UPARSE pipeline (Edgar, 2013) at 97\% similarity, and fungal taxonomic identification was mostly based upon BLASTn searches with a cut-off of $\mathrm{e}=10^{-9}$ against the UNITE database using the 01.12.2017 release version (Koljalg et al., 2005). However, due to some recent reclassifications of fungal taxa (Mayers et al., 2015), the identity of two fungal OTUs was modified, see Supplementary Data S6 for details.

Reads were mapped against OTUs using UPARSE to create an OTU by sample matrix. Fungal OTUs with more than one read in negative control samples were removed from further analyses. Associations only supported by a single read were removed, samples containing fewer than 100 reads in total were also removed, and the dataset was normalized using the cumulative-sum scaling CSS approach (Paulson et al., 2013). Analyses were also run using a rarefied dataset to ensure results were not affected by normalisation method choice (see Supplementary Data S7 for a comparison of results).

\subsection{Statistical analysis}

\subsubsection{The drivers of bark and ambrosia beetle mycobiota}

To assess the relative contribution of beetle species, environmental conditions and spatial distribution to the variability of fungal communities, we applied a variance partitioning approach (Whittaker, 1984; Borcard et al., 1992). Models were built to examine the impact of these three predictor groups on both fungal OTU richness and on fungal OTU community composition.

For the environmental predictors, we conducted a principal component analysis (PCA) to reduce the dimensionality of rainfall and temperature variables taken from both the Worldclim dataset (Worldclim v. 1.4; Hijmans et al., 2005) and from the UK Met Office
Land Surface Observation Stations Dataset (UK Met Office, 2012). The PCA comprised 20 initial variables (Supplementary Data S8), the three components accounting for $89 \%$ of the total variance were retained for further analysis (Supplementary Data S9). Spatial predictors comprised distance-based Moran eigenvector map (dbMEM) variables (Borcard and Legendre, 2002; Dray et al., 2006). This approach reduces the dimensionality of the spatial relationships between study sites into variables which are then used in further analyses to represent these relationships. A subset of four dbMEM variables were retained using the forward selection approach of Blanchet et al. (2008). Principal component analyses and dbMEM calculation and selection were performed using $\mathrm{R}(\mathrm{R}$ Core Team, 2017).

Fungal OTU richness was determined using the Chao1 nonparametric richness estimator (Chao et al., 2009) which was used to generate extrapolated richness. Only beetle species found in two or more locations were used for this analysis, that is 11 species in total, as X. germanus was found only at Thetford. Generalised linear models were made with Poisson errors. Where overdispersion was detected, standard errors were corrected using a quasi-GLM model to reduce overestimating the significance of model predictors (Crawley, 2007; Zuur et al., 2009). All models were built using the stats package in $\mathrm{R}$ ( $\mathrm{R}$ Core Team, 2017).

Permutational multivariate analyses (PERMANOVAs) were conducted to examine the impact of beetle species, environmental and spatial drivers on fungal community composition using the vegan package in $\mathrm{R}$ (Oksanen et al., 2013; R Core Team, 2017). We used the Sørensen index for incidence data. As with the extrapolated fungal OTU richness analysis, variance partitioning was conducted to assess the unique and combined contribution of individual predictors and predictor combinations.

To understand the relative contribution of species replacement (turnover) and species loss (nestedness) to the dissimilarity between fungal communities from different beetle species, an additive partitioning framework following that of Baselga (2010) was used. To achieve this, incidence-based compositional dissimilarity was split into Simpson dissimilarity $\left(\beta_{\text {sim }}\right)$, accounting for turnover, and nestedness-resultant dissimilarity $\left(\beta_{\text {sne }}\right)$ using the betapart package (Baselga and Orme, 2012) in $\mathrm{R}$, which produced two pairwise community dissimilarity matrices. We then used Wilcoxon rank sum tests to compare both beta-diversity components between fungal communities derived from the same beetle species (intraspecific comparisons) and between those derived from different beetle species (interspecific comparisons).

The host specificity of each fungal OTU was calculated using a 
bipartite network based approach similar to that of Toju et al. (2013); for this analysis all 12 beetle species were included. At this point we would like to clarify that this analysis is not able to categorically distinguish symbiotic fungi from non-symbionts, so any perceived host specificity could be due to microhabitat use, host behavioural traits or other non-random factors. The term 'host specificity' as used here is simply a way to indicate that a given fungal OTU is associated with a given subset of beetle species more often than one would expect by chance. The standardised KullbackLeibler distance d' (Kullback and Leibler, 1951; Blüthgen et al., 2006) was calculated with the bipartite package in $R$ (Dormann et al., 2008; R Core Team, 2017). This index uses frequency of association data to assess the 'specificity' of each OTU relative to others, which ranges from 0 (no specificity) to 1 (highly specific). To determine whether fungal OTUs were specific to a particular subset of beetle species, we compared observed d' values with null d' distributions generated from 1,000 randomised matrices (generated using the vaznull model) using a one-tailed permutation test with a $95 \%$ significance cut-off. The vaznull method was deemed the most appropriate because it retains the total number of beetlefungal links for each species, but randomises the identity of the associates. This approach has been used to measure the specificity of pollinators and root-associated fungi (Blüthgen et al., 2006; Toju, 2015) and will indicate which fungal OTUs are restricted to a reduced set of beetle species. If the observed d' index of an OTU is significantly greater than expected by chance based upon comparisons with d' index distributions generated from random networks, it was classed as specific. The proportion of specific and nonspecific fungal OTUs in each fungal order was then compared (Newcombe, 1998). Bonferroni adjustments were applied to each pvalue to reduce the risk of Type I errors.

\section{Results}

\subsection{Sequencing, OTU generation and taxonomic composition}

304 individual beetle specimens were processed for mycobiome analysis. Starting with a total of 17,239,168 paired-end reads, bioinformatic processing reduced the data to $5,416,312$ bidirectional fungal ITS2 sequences. These were grouped into 2,284 nonchimeric OTUs. After removal of OTUs contained within the negative control samples (see Supplementary Data S10 for details) 2,257 OTUs were retained for further analysis. The LCA method in MEGAN indicated no non-fungal OTUs. Out of these, 2,094 OTUs were identified to phylum, 2,012 to class, 1,601 to family and 1,436 were identified to genus level using the UNITE database. Despite only considering those identified ( $93 \%$ of the total number of OTUs found), the taxonomic composition of the fungal communities associated with UK bark and ambrosia beetles was highly diverse (Fig. 1); identified OTUs spanned 32 fungal classes, 214 families and 424 genera. Based on the assigned identity of OTUs, the most prevalent fungal phylum was Ascomycota (73.1\%) and the most common class was Saccharomycetes (27.5\%). Many of the detected taxa have been isolated previously from specimens and galleries of Scolytinae and Platypodinae, including the Microascales genera Ceratocystis, Ambrosiella and Graphium. Additionally, a number of plant pathogens such as Chalara and Cladosporium species were uncovered as well as 41 OTUs belonging to the family Ophiostomataceae.

\subsection{Drivers of bark and ambrosia beetle mycobiota}

When analysing OTU richness, the total amount of explained
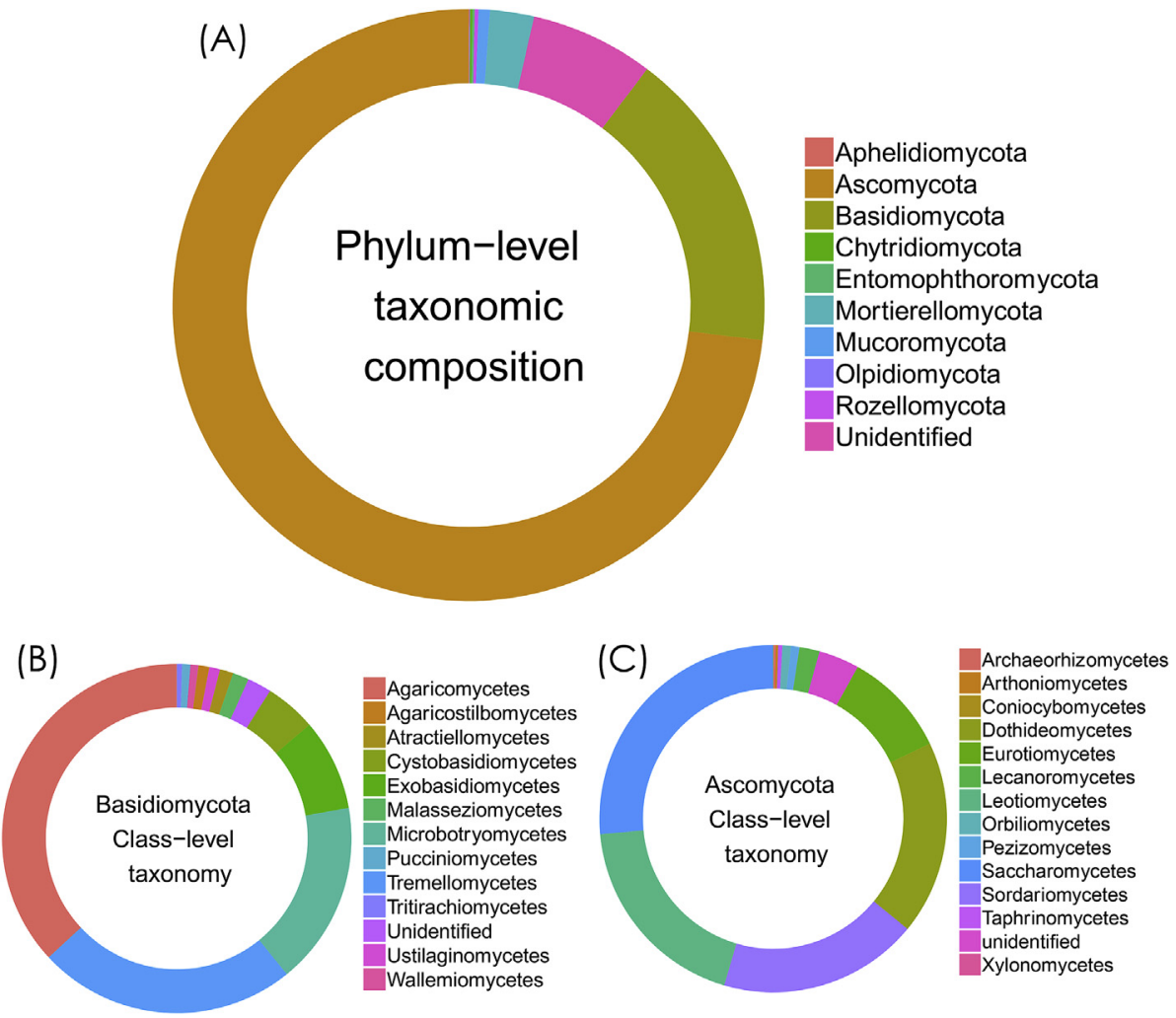

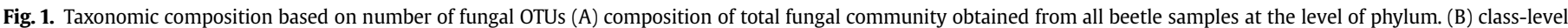

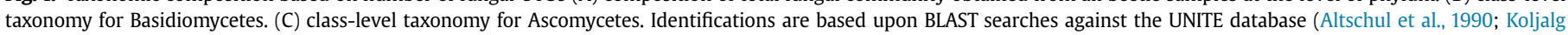
et al., 2005). 
variance over the full model comprising beetle, environmental and spatial predictors was $21.2 \%\left(\mathrm{~F}_{17}, 273=5.9, \mathrm{p}<0.0001\right)$. Beetle species identity uniquely explained $14.5 \%\left(\mathrm{~F}_{10}, 280=4.3, \mathrm{p}<0.0001\right)$ of variation, while environmental and spatial predictors explained $5.3 \%\left(F_{3}, 287=9.36, \mathrm{p}=<0.001\right)$ and $1.5 \%\left(F_{4}, 286=5.28, \mathrm{p}=0.02\right)$ respectively.

For the fungal community analysis, beetle host identity also uniquely explained the greatest proportion of variation: $13.7 \%$. Environmental and spatial variables accounted for little variation independently (between $0.91 \%$ and $2.60 \%$ ), shared variance varied between $0.08 \%$ and $1.46 \%$, and the full model explained $20.92 \%$ (Table 2). See Fig. 2 for an illustration of the dissimilarity between beetle species at each location.

Upon examining the contributions of fungal OTU turnover and nestedness to intraspecies and interspecies mycobiotic dissimilarities, OTU turnover accounted for pairwise dissimilarities between mycobiota to a much greater degree than nestedness for both types of dissimilarity $(\mathrm{W}=48599, \mathrm{p}<0.0001)$ (Fig. 3a). However, nestedness-resultant dissimilarity was significantly higher for intraspecific comparisons ( $\mathrm{W}=160550000, \mathrm{p}<0.0001)$ whilst turnover was significantly lower $(\mathrm{W}=351770000, \mathrm{p}<0.0001)$ (Fig. 3b).

\subsection{The specificity of fungal associates}

Based on the d' specificity metric, 75 fungal OTUs (6.96\%) exhibited a higher association specificity than expected by chance (Fig. 4). The d' index for specific OTUs ranged from 0.041 to 0.498 , and from 0 to 0.275 for non-specific OTUs (based on a randomisation test; see Methods). Of the specific OTUs, 23 (30.7\%) were associated with a single beetle species. Upon examination of the proportion of specific and non-specific OTUs for each fungal order, a high degree of variation in association specificity between closely related OTUs was found. Ten fungal orders contained both specific and non-specific OTUs (Fig. 5). However, when the proportion of specific and non-specific OTUs within each fungal order were compared, two orders exhibited a high number of specific OTUs; the Saccharomycetales $\left(\mathrm{X}=22.86, \mathrm{df}=1, \mathrm{p}=1.75 \times 10^{-05}\right)$ and the Microascales $\left(X=25.59, \mathrm{df}=1, \mathrm{p}=4.23 \times 10^{-06}\right)$.

\section{Discussion}

This community metabarcoding approach for assessing beetle and fungus assemblages gives us an insight into the stringency of symbiotic partnerships, while also revealing the variation in these beetle-fungal associations along environmental and spatial axes. As typical of recent metabarcoding analyses (e.g. Kostovcik et al., 2015; Miller et al., 2016; Malacrinò et al., 2017), we uncovered a large number of fungal OTUs associated with each individual beetle, greatly exceeding those from classical approaches based on culturing and morphology (see Linnakoski et al., 2008; Silva, 2011).

\section{Table 2}

Results from PERMANOVA modeling of incidence-based (Sørensen dissimilarity index) fungal community composition using all predictors, i.e. the full model. Bold type indicates significant p-values.

\begin{tabular}{llll}
\hline Predictor & Pseudo F & $\mathrm{R}^{2}$ & $p$ \\
\hline Beetle species & 5.80 & 0.160 & $\mathbf{0 . 0 0 1}$ \\
Environment component 1 & 3.22 & 0.009 & $\mathbf{0 . 0 0 1}$ \\
Environment component 2 & 2.39 & 0.007 & $\mathbf{0 . 0 0 1}$ \\
Environment component 3 & 2.72 & 0.008 & $\mathbf{0 . 0 0 1}$ \\
dbMEM 2 & 3.47 & 0.010 & $\mathbf{0 . 0 0 1}$ \\
dbMEM 4 & 1.30 & 0.004 & 0.066 \\
dbMEM 5 & 3.57 & 0.010 & $\mathbf{0 . 0 0 1}$ \\
dbMEM 6 & 1.05 & 0.003 & 0.388 \\
\hline
\end{tabular}

Our findings demonstrate that the species identity of beetle hosts is an important determinant of both the richness and composition of the mycobiota, while, within pine plantation communities, the effects of abiotic and spatial factors are essentially negligible at the scale of the British Isles examined here. We then show that the compositional dissimilarity between the mycobiota of individual beetles is largely driven by the turnover of fungal OTUs, but that a larger portion of dissimilarity is attributed to richness differences when looking at beetles from within the same species than between species. Finally, we discovered that a high proportion of yeasts and Microascales are affected by beetle host identity, but that relatively few of the OTUs belonging to the family Ophiostomataceae show an affinity for a particular beetle species. Thus, we confirm that beetle host identity affects the fungal communities vectored between trees, but show that, for the fungal taxa uncovered here, the stringency of association as measured by standard specialisation indices remains low and is driven by a relatively small subset of fungal taxa.

\subsection{The drivers of scolytine-associated fungal communities}

There is a growing number of investigations which examine the fungal communities associated with bark and ambrosia beetles. The economic importance and abundance of these insects has made them an obvious target from an applied perspective and, given the complex history of their symbioses with fungi, they are also an interesting system from an co-evolutionary standpoint (Jordal et al., 2011). Studies have ranged from those focusing on individual beetle species, particularly pests such as Ips typographus (Yamaoka et al., 1997; Jankowiak and Hilszczanski, 2005; Linnakoski et al., 2016) to multiple species (Kostovcik et al., 2015; Skelton et al., 2018), and some have demonstrated variability between the mycobiota of different beetle species. However, to our knowledge none have attempted to quantify the relative importance of host species and environmental drivers such as done here. The results of this analysis show that while these fungal assemblages are difficult to predict based on the drivers we examine, host beetle species does explain more variation than climate and geographic location. The additive partitioning analysis, which revealed that fungal OTU turnover $\left(\beta_{\text {sim }}\right.$ showed a greater contribution than nestedness ( $\beta$ sne) to differences between mycobiota, thus indicating that diversity patterns are driven by the substitution of fungal OTUs between beetle individuals rather than the loss of OTUs between them (Baselga, 2010, 2012). However, the fact that nestedness was significantly higher and turnover significantly lower for intraspecific comparisons suggests that more OTUs are shared between fungal communities derived from the same beetle species, but each individual only carries a certain portion of that community. This result is consistent with the significant but low level of variance explained in the OTU composition analysis and the relatively small proportion of host specific fungal taxa uncovered in the specificity analysis.

The relatively small effect of environmental and spatial model variables suggests that these factors only play a minor role in the composition and richness of bark and ambrosia beetle mycobiota in our system. Both temperature and precipitation have been shown to affect fungal community richness and composition across a wide range of habitats and functional groups (Rudgers et al., 2015), and environmental change can demonstrably remove microbial associates from a symbiosis (Kikuchi et al., 2016). However, climate is expected to have a reduced effect on the composition of hostassociated rather than free-living communities, as hosts can be seen to represent 'islands' of suitable habitat and thus reduce habitat selection pressure (Peay et al., 2016). Similarly, spatial separation is a major determinant of microbial community 

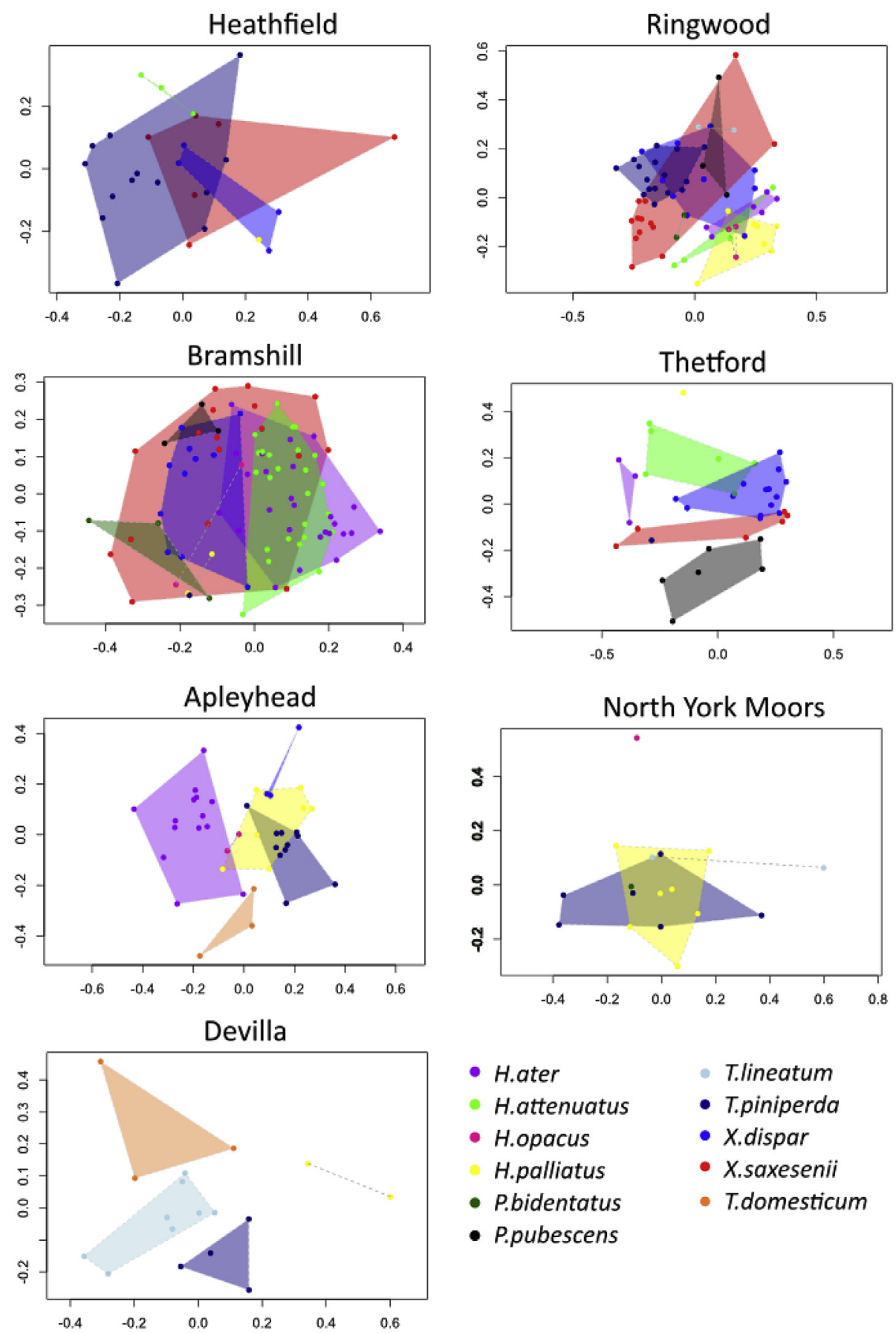

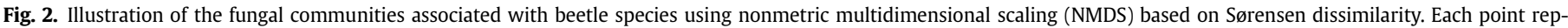
resents the mycobiota of an individual beetle specimen. Colours represent beetle species. Culbin was left out of this figure as it only contained two beetle species.

similarity in some systems (Córdova-Kreylos et al., 2006; Langenheder and Székely, 2011) but is seemingly unimportant in others (Van der Gucht et al., 2007; Winter et al., 2013). Our results mirror the latter studies, and a possible explanation for this rests on the dispersal abilities of scolytines. Whilst many European studies suggest that bark beetles generally migrate less than $2 \mathrm{~km}$ during their lifetime (Zumr, 1992; Duelli et al., 1997; Costa et al., 2013), under outbreak conditions passive wind dispersal at high altitudes can enable beetles to migrate much further (Jackson et al., 2008). Should this occur, it is likely to promote convergence between the mycobiota of beetle individuals from different populations. Additionally, the climatic gradient used here may not have been large enough to constrain fungal species distributions, and the fact that this study was restricted to pine forest would have further constrained variability in fungal communities (Giordano et al., 2012; Purahong et al., 2018).

\subsection{Richness and composition of beetle-associated fungi}

The deeper level of sequencing, higher resolution of species level identifications, and the removal of media selection bias can enable metabarcoding approaches to show a more complete 
(A)

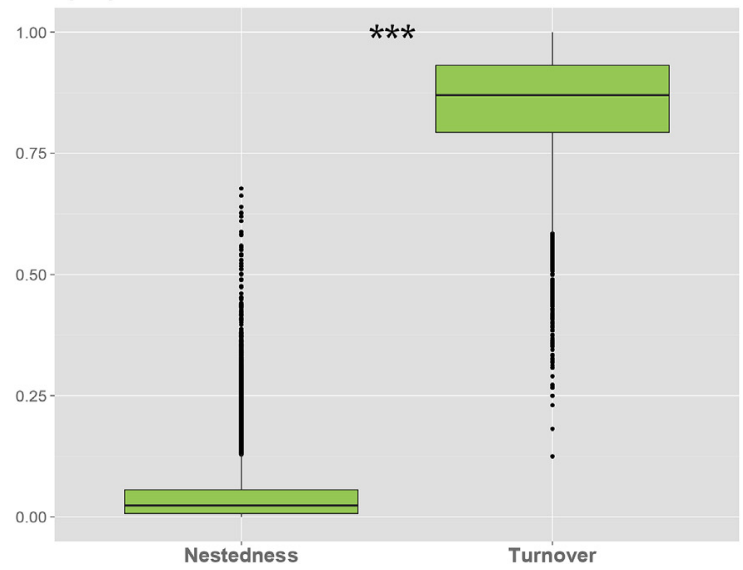

(B)

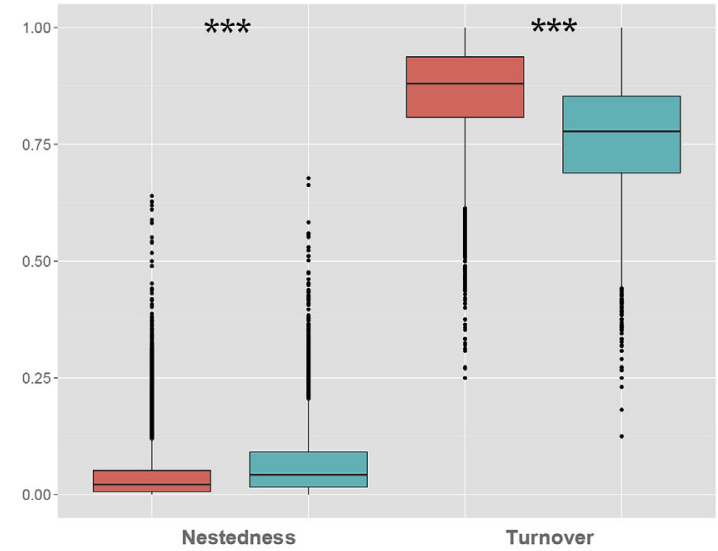

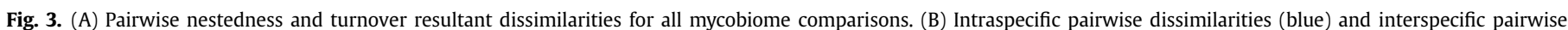
dissimilarities (red) between mycobiota. Stars represent significant differences between levels $(p<0.05)$.

picture of microbial communities (O'Brien et al., 2005; Jackson et al., 2013; Sinclair et al., 2015). Yet, methodological issues must be considered. The ITS2 marker often comprises just under $300 \mathrm{bp}$, limiting its power of species resolution. It is also present in multiple copies, which may vary within an individual genome potentially resulting in artificially inflated OTU richness. Conversely, clustering at $97 \%$ could potentially combine closely related fungal species into the same OTU, artificially reducing OTU richness. Both of these outcomes would impact the network-based specificity analysis, the former could conceivably lead to an exaggeration of specificity levels while the latter would lead to an underestimation of specificity. However, the fact that we were able to reconstruct known associations (Ambrosiella grosmanniae, Phialophoropsis ferruginea, and Ambrosiella hartigii were all found to demonstrate significant specificity to their expected hosts: X. germanus, the two Trypodendron species, and Anisandrus dispar respectively) gives us confidence that these methodological issues, despite creating 'noise' in the dataset, have not masked clear ecological patterns. We believe that our treatment of the sequence data is conservative due to stringent parameters for sequence error removal, the elimination of low-abundance OTUs, and the use of HMM profiles to identify ITS2 sequences. In addition to high OTU diversity, the composite mycobiome of all beetle species was taxonomically diverse, represented by a wide range of taxa including many ophiostomatoid fungi. This finding is consistent with previous investigations into scolytine-associated fungi and known ecological associations of these groups (Harrington, 2005; Silva, 2011; Giordano et al., 2012). Members of the well represented class Dothideomycetes are usually saprotrophs associated with decaying plant material, while species in the equally highly represented class Sordariomycetes, which includes the harmful Microascales, often dominate communities in forests (O'Brien et al., 2005; Lauber et al., 2008; Meiser et al., 2013). Having said this, the primers utilised for this study are known to have a low affinity for ophiostomatoid fungi in the genus Raffaelea (Kostovcik et al., 2015), and this is reflected by the absence of any Raffaelea species amplified. Many Raffaelea are phytopathogens and some are believed to display high affinities for particular beetle hosts (Rabern Simmons et al., 2016). As such, we are careful to avoid generalising our results to suggest that all ophiotomatoid fungi have low host affinity, but rather that this is true for the 41 uncovered here.

Members of the Microascales, including known bark beetle symbionts in the genera Graphium, Ceratocystis and Ambrosiella
(Klepzig et al., 2001), were recognised against the well-curated UNITE database and were among the OTUs classified as hostspecific. Three OTUs in particular closely matched the barcode accessions of described fungal symbionts allowing species-level identifications that were also supported by known host distributions. Close database matches to the well-studied obligate fungal symbionts $A$. hartigii, A. grosmanniae sp. nov. and $P$. ferruginea were supported by recovery from their known hosts, $A$. dispar, $X$. germanus, and both Trypodendron domesticum and Trypodendron lineatum respectively (Batra, 1963; French and Roeper, 1972a,b; Skelton et al., 2018). These fungi are obligate symbionts and are 'farmed' and fed upon by these ambrosia beetles. Additionally, an OTU matched database accessions of the Hypocreales Geosmithia langdonii, which was only found in Pityogenes bidentatus individuals. While known to be associated with bark beetles, the ecological role of this apparent symbiont is not well understood.

Among the class Saccharomycetes we detected a large number of OTUs. Ascomycetous yeasts have been found with all developmental stages of bark and ambrosia beetles (Callaham and Shifrine, 1960; Francke-Grosmann, 1967; Davis, 2015), but their ubiquitous distribution has led to suggestions that they do not exhibit affiliations with particular beetle species (Six, 2003). Our finding calls this assertion into question. For example, we found the genus Metschnikowia to be overrepresented among the host-specific OTUs. Metschnikowia is a genus of insect-associated fungi that have been isolated from various bark beetles, including I. typographus and Dendroctonus micans (Weiser et al., 2003; Yaman and Radek, 2008), but here it was almost exclusively found in nonambrosial bark beetles, specifically Hylastes ater and Hylurgops palliatus, which have no known obligate fungal associations (Reay et al., 2001; Romón et al., 2007). Although little is known about their life history, Metschnikowia species comprise insect pathogens (Weiser et al., 2003) suggesting that the associations observed here may reflect a specific parasitic relationship with a narrow range of beetle hosts. Other cases include the yeasts Ogataea pini and Kuraishia capsulata, which were only found in individuals of $P$. bidentatus. These fungal species are associates of the scolytine genera Ips, Dendroctonus and Scolytus (Yamada et al., 1994; Kolarík et al., 2007; Davis, 2015). O. pini produces volatiles that reduce the growth of entomopathogenic fungi (Davis et al., 2011). We are not currently aware of any studies that have expressly investigated the specificity of host-associated yeast, but 


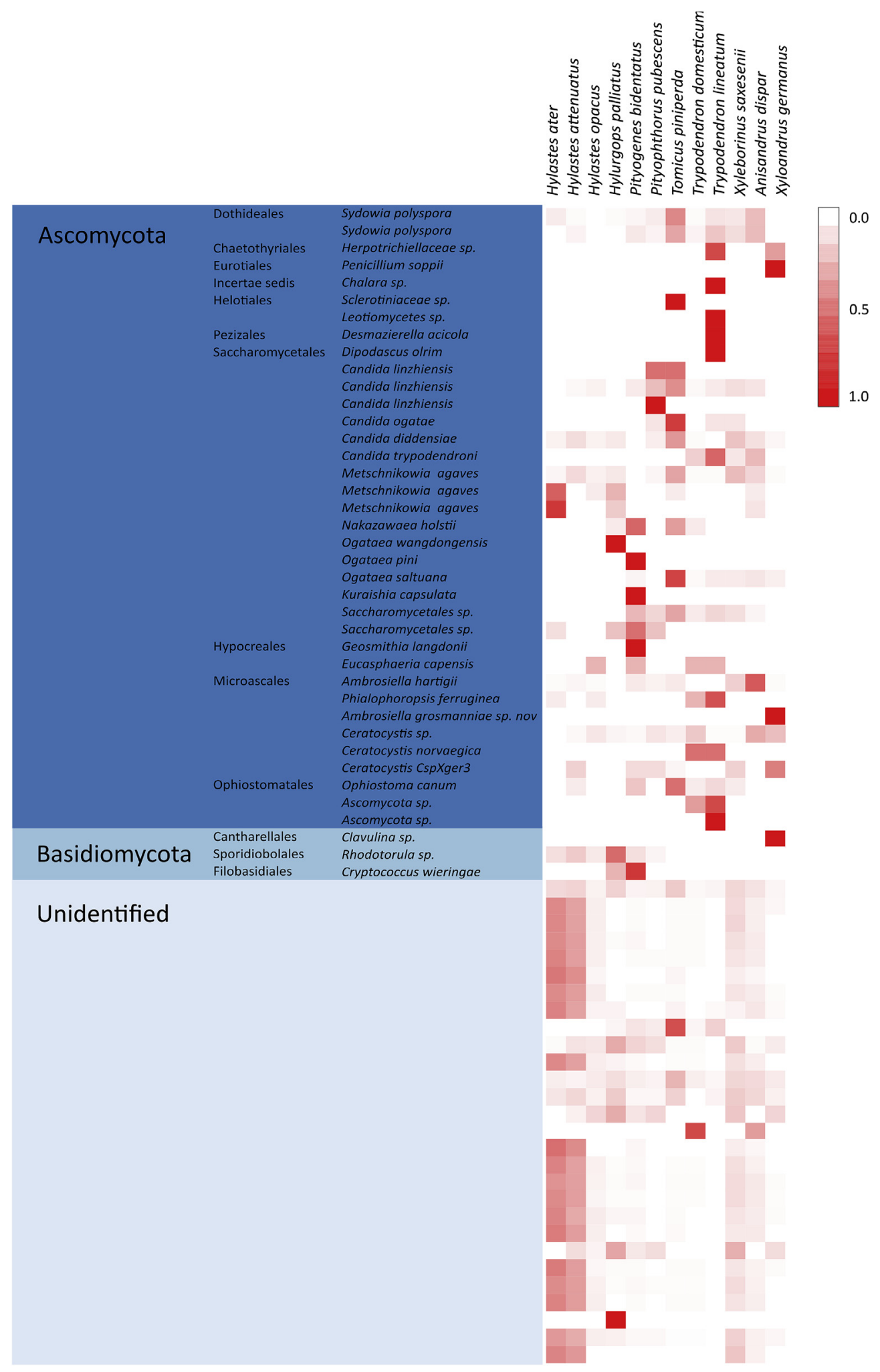

Fig. 4. Association specificity analysis showing the distribution of the specific OTUs across beetle species. Red squares indicate the strength of association between each OTU and beetle as a proportion of the total number of occurrences for each OTU ranging between 0 (the OTU was not found to associate with any specimens of a beetle species) and 1 (the OTU was only found to associate with a single beetle species). 


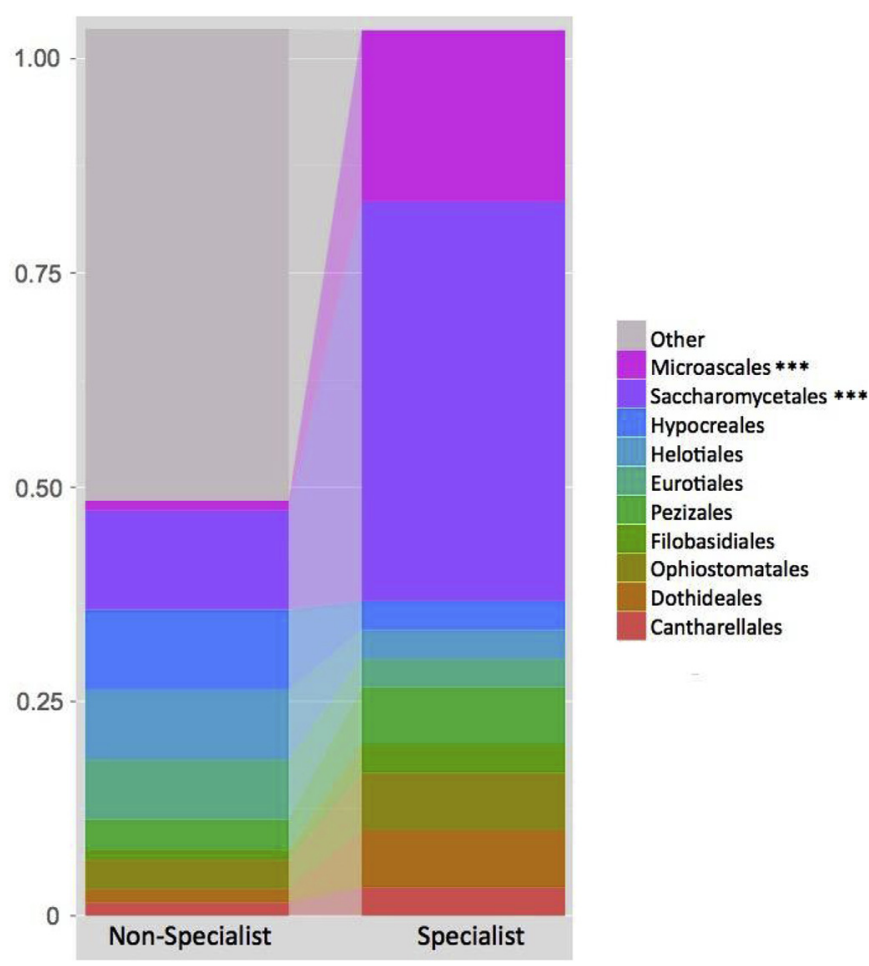

Fig. 5. Proportion of non-specific and specific OTUs for ten fungal orders. Stars indicate a significant difference in the proportions $(p<0.005)$. Classification of OTUs is based upon bipartite network analysis.

suggest that an analysis of this kind may reveal many more mutualistic and antagonistic relationships.

As touched upon previously, 'host specific' OTUs demonstrate an affinity to a subset of beetle species, this may be due to a symbiotic relationship or to another reason. For example, certain beetle species may come into contact with spores from a particular fungus due to behavioural preferences like overwintering in leaf litter as opposed to under bark, and it may be that there is no symbiosis occurring between the two taxa. It should also be noted, that an absence of specificity does not necessarily confirm a lack of symbiosis. Symbioses are increasingly understood to comprise a broad range of association types and current paradigms are moving away from traditional classifications (Leung and Poulin, 2008). Traditional ecological theory posits that specialisation reduces competition and is, therefore, the normal consequence of coevolution (Futuyma and Moreno, 1988). Because specialist symbionts typically exhibit lower fitness when interacting with sub-optimal host species, it has been argued that specialisation is irreversible and can lead to an 'evolutionary dead end' (Huxley, 1942; Poulin, 2007). However, recent studies suggest that generalism can also be adaptive and there is now empirical evidence supporting the assertion that transitions from specialist to generalist life histories can indeed occur (Nosil, 2002; Poulin et al., 2006; Johnson et al., 2009; Skelton et al., 2019). Further, it is becoming increasingly clear that facultative microbial symbionts play important roles in the structuring of whole communities (Ferrari and Vavre, 2011; Frago et al., 2012), although these taxa can be distributed across multiple host species and occurrence can be contingent upon external factors (Mitsuhashi et al., 2002; Chiel et al., 2009). In sum, our focus on specialisation as an indication of an association is the result of using a whole community, exploratory approach and is a useful first step in gaining a better understanding of such systems. Further work is certainly needed to clarify the nature of these relationships, such as the isolation and culture of these fungal species to elucidate identities and experimental work to assess the effects of manipulating the incidence of putative symbionts.

\section{Conclusions}

Earlier studies of mycobiota associated with bark and ambrosia beetles suggested that particular beetle species form close, specific associations with a small number of fungal taxa (Beaver, 1989; Cardoza et al., 2009). However, recent molecular-based analyses show that these fungal communities are much more diverse and promiscuous than originally thought (Kostovcik et al., 2015), potentially indicating the presence of facultative symbiosis and many non-specific associations. Our results are partially consistent with both of these conclusions: we demonstrate that although beetle host identity has a stronger explanatory power than environmental or spatial factors, it still explains less than $20 \%$ of the total variance in composition, and only a small subset of fungal taxa appear to be driving the trend. This pattern could be explained by the presence of a diverse array of fungal taxa exhibiting associations spanning the entire specificity spectrum, as well as incidental or transient associates not partaking in interactions at all. Our network analysis allowed us to identify 'host specific' taxa from this large diversity of fungi, some of which were expected symbionts, while others were poorly known yeasts whose tight associations may have been previously overlooked. However, these understudied taxa may well be important players within scolytine-driven dynamic forest systems. The fact that some fungal taxa were associated with novel insect species highlights the utility of adopting modern molecular approaches to re-examine established associations. Finally, despite identifying 41 fungal OTUs in the family Ophiostomatacea, only two showed host specificity indicating that the vectoring of these taxa is not restricted to particular beetle species. This finding has clear implications for the monitoring and management of an important group of forest pathogens. For instance, the low levels of specificity shown here could indicate a high probability of disassociation and host switching indicating that the environmental conditions that limit the distribution of a host may not limit the spread of an associated pathogen. This picture would be improved by investigating the distribution of Raffaelea species within this community as these may prove to buck the trend observed here for ophiostomatoid taxa. The role of biotic interactions in shaping fungal biogeography is relatively unexplored, but there is mounting evidence that it plays a crucial role in determining community composition. Only with more examples of natural host-fungus community assemblages can we assess its influence under different scenarios and across divergent fungal taxa.

\section{Data accessibility statement}

Sequence-based fungal community data: European Nucleotide Archive, Accession Number: PRJEB33668.

\section{Acknowledgements}

This study was supported by a Natural Environment Research Council PhD scholarship (ref: 1136825), and by the Natural History Museum, London Biodiversity Initiative. Funding and logistic support for fieldwork was provided by the Forestry Commission.

\section{Conflicts of interest}

APV is a co-founder of NatureMetrics, a company delivering commercial services in molecular biomonitoring. 


\section{Supplementary data}

Supplementary data to this article can be found online at https://doi.org/10.1016/j.funeco.2019.07.008.

KEM, DJGI and APV designed the study; KEM and DJGI conducted fieldwork; KEM designed and conducted labwork and bioinformatics; KEM conducted analysis under the supervision of CGR, $\mathrm{AB}$ and $\mathrm{APV}, \mathrm{KEM}$ and $\mathrm{APV}$ wrote the paper with contribution from all authors.

\section{References}

Altschul, S.F., Gish, W., Miller, W., Myers, E.W., Lipman, D.J., 1990. Basic local alignment search tool. J Mol Biol. 215 (3), 403-410.

Andrews, S., 2010. FastQC: a Quality Control Tool for High Throughput Sequence Data. http://www.bioinformatics.babraham.ac.uk/projects/fastqc.

Aronesty, E., 2011. Ea-Utils: Command-Line Tools for Processing Biological Sequencing Data. Expression Analysis, Durham, NC. http://code.google.com/p/ ea-utils.

Baselga, A., 2010. Partitioning the turnover and nestedness components of beta diversity. Glob. Ecol. Biogeogr. 19, 134-143.

Baselga, A., Orme, C.D.L., 2012. betapart: an R package for the study of beta diversity. Methods Ecol. Evol. 3, 808-812.

Batra, 1963. Ecology of ambrosia fungi and their dissemination by beetles. Trans. Kans. Acad. Sci. 66, 213-236.

Beaver, R., 1989. Insect-fungus relationships in the bark and ambrosia beetles. In: Wilding, N., Colins, N., Hammond, P., Webber, J. (Eds.), Insect-Fungus Interactions. 14th Symposium of the Royal Entomological Society of London in Collaboration with the British Mycological Society. Academic Press, Inc, pp. 121-143.

Bengtsson-Palme, J., Ryberg, M., Hartmann, M., Branco, S., Wang, Z., Godhe, A., De Wit, P., Sánchez-García, M., Ebersberger, I., de Sousa, F., Amend, A.S., Jumpponen, A., Unterseher, M., Kristiansson, E., Abarenkov, K., Bertrand, Y.J.K., Sanli, K., Eriksson, K.M., Vik, U., Veldre, V., Nilsson, R.H., 2013. Improved software detection and extraction of ITS1 and ITS2 from ribosomal ITS sequences of fungi and other eukaryotes for analysis of environmental sequencing data. Methods Ecol. Evol. 4, 914-919.

Biedermann, P.H.W., Klepzig, K.D., Taborsky, M., Six, D.L., 2012. Abundance and dynamics of filamentous fungi in the complex ambrosia gardens of the primitively eusocial beetle Xyleborinus saxesenii Ratzeburg (Coleoptera: Curculionidae, Scolytinae). FEMS (Fed. Eur. Microbiol. Soc.) Microbiol. Ecol. 83, 711-723.

Blanchet, F.G., Legendre, P., Borcard, D., 2008. Forward selection of explanatory variables. Ecology 89, 2623-2632.

Blüthgen, N., Menzel, F., Blüthgen, N., 2006. Measuring specialization in species interaction networks. BMC Ecol. 6, 9.

Borcard, D., Legendre, P., 2002. All-scale spatial analysis of ecological data by means of principal coordinates of neighbour matrices. Ecol. Model. 153, 51-68.

Borcard, D., Legendre, P., Drapeau, P., 1992. Partialling out the spatial component of ecological variation. Ecology 73, 1045-1055.

Brasier, C.M., 1991. Ophiostoma novo-ulmi sp. nov., causative agent of current Dutch elm disease pandemics. Mycopathologia 115, 151-161.

Callaham, R.Z., Shifrine, M., 1960. The yeasts associated with bark beetles. For. Sci. 6, 146-154.

Caporaso, J.G., Kuczynski, J., Stombaugh, J., Bittinger, K., Bushman, F.D., Costello, E.K., Fierer, N., Peña, A.G., Goodrich, J.K., Gordon, J.I., Huttley, G.A., Kelley, S.T., Knights, D., Koenig, J.E., Ley, R.E., Lozupone, C.A., McDonald, D., Muegge, B.D., Pirrung, M., Reeder, J., Sevinsky, J.R., Turnbaugh., P.J., Walters, W.A., Widmann, J., Yatsunenko, T., Zaneveld, J., Knight, R., 2010. QIIME allows analysis of highthroughput community sequencing data. Nat. Methods 7, 335-336.

Cardoza, Y., Vasanthakumar, A., Suazo, A., Raffa, K., 2009. Survey and phylogenetic analysis of the culturable microbial fauna in the oral secretions of three bark beetle species. Entomol. Exp. Appl. 131, 138-147.

Cassier, P., Lévieux, J., Morelet, M., Rougon, D., 1996. The mycangia of Platypus cylindrus Fab. and P. oxyurus Dufour (Coleoptera: platypodidae). Structure and associated fungi. J. Insect Physiol. 42, 171-179.

Chao, A., Colwell, R.K., Lin, C.-W., Gotelli, N.J., 2009. Sufficient sampling for asymptotic minimum species richness estimators. Ecology 90, 1125-1133.

Chiel, E., Zchori-Fein, E., Inbar, M., Gottlieb, Y., Adachi-Hagimori, T., Kelly, S.E., Asplen, M.K., Hunter, M.S., 2009. Almost there: transmission routes of bacterial symbionts between trophic levels. PLoS One 0004767.

Córdova-Kreylos, A.L., Cao, Y., Green, P.G., Hwang, H.M., Kuivila, K.M., Lamontagne, M.G., Van De Werfhorst, L.C., Holden, P.A., Scow, K.M., 2006. Diversity, composition, and geographical distribution of microbial communities in California salt marsh sediments. Appl. Enviromental Microbiol. 72, 3357-3366.

Costa, A., Min, A., Boone, C.K., Kendrick, A.P., Murphy, R.J., Sharpee, W.C., Raffa, K.F., Reeve, J.D., 2013. Dispersal and edge behaviour of bark beetles and predators inhabiting red pine plantations. Agric. For. Entomol. 15, 1-11.

Crawley, M.J., 2007. The R Book. Wiley Publishing.

Davis, T.S., 2015. The ecology of yeasts in the bark beetle holobiont: a century of Research revisited. Microb. Ecol. 69, 723-732.

Davis, T.S., Hofstetter, R.W., Foster, J.T., Foote, N.E., Keim, P., 2011. Interactions between the yeast Ogataea pini and filamentous fungi associated with the western pine beetle. Microb. Ecol. 61, 626-634.

Dormann, C.F., Gruber, B., Fruend, J., 2008. Introducing the bipartite package: analysing ecological networks. R. News 8, 8-11.

Dray, S., Legendre, P., Peres-Neto, P.R., 2006. Spatial modelling: a comprehensive framework for principal coordinate analysis of neighbour matrices (PCNM). Ecol. Model. 196, 483-493.

Duelli, P., Zahradnik, P., Knizek, M., Kalinova, B., 1997. Migration in spruce bark beetles (Ips typographus L.) and the efficiency of pheromone traps. J. Appl. Entomol. 121, 297-303.

Duffy, E.A.J., 1953. Coleoptera (Scolytidae and Platypodidae). Handbooks for the Identification of British Insects. Royal Entomological Society, London vol. 5, part 15.

Dumbrell, A.J., Ashton, P.D., Aziz, N., Feng, G., Nelson, M., Dytham, C., Fitter, A.H. Helgason, T., 2011. Distinct seasonal assemblages of arbuscular mycorrhizal fungi revealed by massively parallel pyrosequencing. New Phytol. 190, 794-804.

Edgar, R.C., 2013. UPARSE: highly accurate OTU sequences from microbial amplicon reads. Nat. Methods 10, 996-998.

Endoh, R., Suzuki, M. Okada, G., Takeuchi, Y., Futai, K., 2011. Fungus symbionts colonizing the galleries of the ambrosia beetle platypus quercivorus. Microb. Ecol. 62, 106-120.

Ferrari, J., Vavre, F., 2011. Bacterial symbionts in insects or the story of communities affecting communities. Philos. Trans. R. Soc. Biol. Sci. 366, 1389-1400.

Fraedrich, S.W., Harrington, T.C., Best, G.S., 2015. Xyleborus glabratus attacks and systemic colonization by Raffaelea lauricola associated with dieback of Cinnamomum camphora in the southeastern United States. For. Pathol. 45, 60-70.

Frago, E., Dicke, M., Godfray, H.C.J., 2012. Insect symbionts as hidden players in insect-plant interactions. Trends Ecol. Evol. 27, 705-711.

Francke-Grosmann, H., 1967. Ectosymbiosis in wood-inhabiting insects. In: Henry, S.M. (Ed.), Symbiosis, Vol 2 Associations of Invertebrates, Birds, Ruminants and Other Biota. Academic Press, New York, pp. 141-206.

French, J., Roeper, R., 1972a. In-vitro culture of ambrosia beetle Xyleborus dispar (Coleoptera-Scolytidae) with its symbiotic fungus, Ambrosiella hartigii (fungiimperfecti). Ann. Entomol. Soc. Am. 65, 719-721.

French, J., Roeper, R., 1972b. Interactions of ambrosia beetle, Xyleborus dispar (Coleoptera Scolytidae), with its symbiotic fungus Ambrosiella hartigii (fungi imperfecti). Can. Entomol. 104, 1635-1641.

Futuyma, D.J., Moreno, G., 1988. The evolution of ecological specialization. Annu. Rev. Ecol. Systemat. 19, 207-233.

Giordano, L., Garbelotto, M., Nicolotti, G., Gonthier, P., 2012. Characterization of fungal communities associated with the bark beetle Ips typographus varies depending on detection method, location, and beetle population levels. Mycol Prog. 12, 127-140.

Grüne, S., 1979. Handbuch zur Bestimmung der europaischen Borkenkafer - Brief Illustrated Key to European Bark Beetles. Schaper, Hannover.

van der Gucht, K., Cottenie, K., Muylaert, K., Vloemans, N., Cousin, S., Declerck, S. Jeppesen, E., Conde-Porcuna, J.M., Schwenk, K., Zwart, G., Degans, H. Vyverman, W., De Meester, L., 2007. The power of species sorting: local factors drive bacterial community composition over a wide range of spatial scales, Proc. Natl. Acad. Sci. 104, 20404-20409.

Haack, R.A., 2006. Exotic bark- and wood-boring Coleoptera in the United States: recent establishments and interceptions. Can. J. For. Res. 36, 269-288.

Harrington, T., 2005. Ecology and evolution of mycophagous bark beetles and their fungal partners. In: Vega, F.E., Blackwell, M. (Eds.), Ecological and Evolutionary Advances in Insect-Fungal Associations. Oxford University Press, pp. 257-291.

Hazard, C., Gosling, P., van der Gast, C.J., Mitchell, D.T., Doohan, F.M., Bending, G.D. 2013. The role of local environment and geographical distance in determining community composition of arbuscular mycorrhizal fungi at the landscape scale. ISME J 7, 498-508.

Hijmans, R.J., Cameron, S.E., Parra, J.L., Jones, P.G., Jarvis, A., 2005. Very high resolution interpolated climate surfaces for global land areas. Int. J. Climatol. 25, 1965-1978.

Hulcr, J., Atkinson, T.H., Cognato, A.I., Jordal, B.H., McKenna, D.D., 2015. Morphology, taxonomy and phylogenetics of bark beetles. In: Vega, F.E., Hofstetter, R.W. (Eds.), Bark Beetles: Biology and Ecology of Native and Invasive Species. Academic Press, San Diego, pp. 41-84.

Hulcr, J., Kolarik, M., Kirkendall, L.R., 2007. A new record of fungus-beetle symbiosis in Scolytodes bark beetles (Scolytinae, Curculionidae, Coleoptera). Symbiosis 43, 151-159.

Hulcr, J.1, Rountree, N.R., Diamond, S.E., Stelinski, L.L., Fierer, N., Dunn, R.R., 2012 Mycangia of ambrosia beetles host communities of bacteria. Microb Ecol. 64 (3), 784-793.

Huxley, J., 1942. Evolution: the Modern Synthesis. Harper and Brothers.

Jackson, C.R., Randolph, K.C., Osborn, S.L., Tyler, H.L., 2013. Culture dependent and independent analysis of bacterial communities associated with commercial salad leaf vegetables. BMC Microbiol. 13, 274.

Jackson, P.L., Straussfogel, D., Lindgren, B.S., Mitchell, S., Murphy, B., 2008. Radar observation and aerial capture of mountain pine beetle, Dendroctonus ponderosae Hopk. (Coleoptera : scolytidae) in flight above the forest canopy. Can. J. For. Res. 38, 2313-2327.

Jacobsen, R.M., Kauserud, H., Sverdrup-Thygeson, A., Bjorbækmo, M.M., Birkemoe, T., 2017. Wood-inhabiting insects can function as targeted vectors for decomposer fungi. Fungal Ecol. 29, 76-84.

Jankowiak, R., Hilszczanski, J., 2005. Ophiostomatoid fungi associated with Ips 
typographus (L.) on Picea abies (L.) and Pinus sylvestris (L.) in north-eastern Poland. Acta Soc. Bot. Pol. 74, 345-350.

Johnson, K.P., Malenke, J.R., Clayton, D.H., 2009. Competition promotes the evolution of host generalists in obligate parasites. Proc. R. Soc. Biol. Sci. 276, 3921-3926.

Jordal, B.H., Sequeira, A.S., Cognato, A.I., 2011. The age and phylogeny of wood boring weevils and the origin of subsociality. Mol. Phylogenetics Evol. 59, $708-724$.

Kikuchi, Y., Tada, A., Musolin, D.L., Hari, N., Hosokawa, T., Fujisaki, K., Fukatsu, T., 2016. Collapse of insect gut symbiosis under simulated climate change. mBio 7 e01578-16.

Kirisits, T., 2004. Fungal associates of European bark beetles with special emphasis on the ophiostomatoid fungi. In: Lieutier, F., Day, K., Battisti, A., Gregoire, J. Evans, H. (Eds.), Bark and Wood Boring Insects in Living Trees in Europe, a Synthesis. Springer, Dordrecht, pp. 181-235.

Kirkendall, L.R., Faccoli, M., 2010. Bark beetles and pinhole borers (Curculionidae, Scolytinae, Platypodinae) alien to Europe. ZooKeys 56, 227-251.

Klepzig, K.D., Moser, J.C., Lombardero, F.J., Hofstetter, R.W., Ayres, M.P., 2001. Symbiosis and competition: complex interactions among beetles, fungi and mites. Symbiosis 30, 83-96.

Kolarík, M., Kubátová, A., Hulcr, J., Pazoutová, S., 2007. Geosmithia fungi are highly diverse and consistent bark beetle associates: evidence from their community structure in temperate Europe. Microb. Ecol. 55, 65-80.

Koljalg, U., Larsson, K.H., Abarenkov, K., Nilsson, R.H., Alexander, I.J., Eberhardt, U., Erland, S., Høiland, K., Kjøller, R., Larsson, E., Pennanen, T., Sen, R., Taylor, A.F. Tedersoo, L., Vrålstad, T., Ursing, B.M., 2005. UNITE: a database providing webbased methods for the molecular identification of ectomycorrhizal fungi. New Phytol. 166, 1063-1068.

Kostovcik, M., Bateman, C.C., Kolarik, M., Stelinski, L.L., Jordal, B.H., Hulcr, J., 2015 The ambrosia symbiosis is specific in some species and promiscuous in others: evidence from community pyrosequencing. ISME J 9, 126-138.

Krokene, P., Solheim, H., 1998. Pathogenicity of four blue-stain fungi associated with aggressive and nonaggressive bark beetles. Phytopathology 88, 39-44.

Kullback, S., Leibler, R.A., 1951. On information and sufficiency. Ann. Math. Stat. 22 79-86.

Langenheder, S., Székely, A.J., 2011. Species sorting and neutral processes are both important during the initial assembly of bacterial communities. ISME J. 5, 1086-1094.

Lauber, C.L., Strickland, M.S., Bradford, M. a., Fierer, N., 2008. The influence of soil properties on the structure of bacterial and fungal communities across land-use types. Soil Biol. Biochem. 40, 2407-2415.

Leung, T.L.F., Poulin, R., 2008. Parasitism, commensalism, and mutualism: exploring the many shades of symbioses. Vie Milieu Life Environ. 58, 107-115.

Linnakoski, R., De Beer, Z.W., Rousi, M., Niemelä, P., Pappinen, A., Wingfield, M.J. 2008. Fungi, including Ophiostoma karelicum sp nov., associated with Scolytus ratzeburgi infesting birch in Finland and Russia. Mycol. Res. 112, 1475-1488.

Linnakoski, R., Mahilainen, S., Harrington, A., Vanhanen, H., Eriksson, M., Mehtätalo, L., Pappinen, A., Wingfield, M.J., 2016. Seasonal succession of fung associated with Ips typographus beetles and their Phoretic mites in an outbreak region of Finland. PLoS One 11.

Malacrinò, A., Rassati, D., Schena, L., Mehzabin, R., Battisti, A., Palmeri, V., 2017. Fungal communities associated with bark and ambrosia beetles trapped at international harbours. Fungal Ecol. 28, 44-52.

Mayers, C.G., McNew, D.L., Harrington, T.C., Roeper, R.A., Fraedrich, S.W Biedermann, P.H.W., Castrillo, L.A., Reed, S.E., 2015. Three genera in the Ceratocystidaceae are the respective symbionts of three independent lineages of ambrosia beetles with large, complex mycangia. Fungal Biol. 119 (11) 1075-1092.

McIntosh, R.L., Katinic, P.J., Allison, J.D., Borden, J.H., Downey, D.L., 2001. Comparative efficacy of five types of trap for woodborers in the Cerambycidae Buprestidae and Siricidae. Agric. For. Entomol. 3, 113-120.

Meiser, A., Bálint, M., Schmitt, I., 2013. Meta-analysis of deep-sequenced funga communities indicates limited taxon sharing between studies and the presence of biogeographic patterns. New Phytol. 201, 623-635.

Met Office, 2012. Met Office integrated data archive system (MIDAS) land and marine surface Stations data (1853-current). NCAS Br. Atmos. Data Cent.

Miller, K.E., Hopkins, K., Inward, D.J.G., Vogler, A.P., 2016. Metabarcoding of fungal communities associated with bark beetles. Ecol. Evol. 6, 1590-1600.

Mitsuhashi, W., Saiki, T., Wei, W., Kawakita, H., Sato, M., 2002. Two novel strains of Wolbachia coexisting in both species of mulberry leafhoppers. Insect Mol. Biol. $11,577-584$

Newcombe, R.G., 1998. Two-sided confidence intervals for the single proportion: comparison of seven methods. Stat. Med. 17, 857-872.

Nosil, P., 2002. Transition rates between specialization and generalization in phytophagous insects. Evolution 56, 1701-1706.

O'Brien, H.E., Parrent, J.L., Jackson, J.A., Moncalvo, J., 2005. Fungal community analysis by large-scale sequencing of environmental samples. Appl. Environ. Microbiol. 71, 5544-5550.

Oksanen, J.F., Blanchet, G., Kindt, R., Legendre, P., Minchin, P.R., O'Hara, R.B. Simpson, G.L., Solymos, P., Stevens, H.H., Wagner, H.V., 2013. Vegan: Community Ecology Package. $\mathrm{R}$ package version 2.5-5. https://CRAN.R-project.org/ package = vegan.

Öpik, M., Moora, M., Liira, J., Zobel, M., 2006. Composition of root-colonizing arbuscular mycorrhizal fungal communities in different ecosystems around the globe. J. Ecol. 94, 778-790.
Paine, T.D., Raffa, K.F., Harrington, T.C., 1997. Interactions among Scolytid bark beetles, their associated fungi, and live host conifers. Annu. Rev. Entomol. 42. 179-206.

Paulson, J.N., Colin Stine, O., Bravo, H.C., Pop, M., 2013. Differential abundance analysis for microbial marker-gene surveys. Nat. Methods 10, 1200-1202.

Peay, K.G., Kennedy, P.G., Talbot, J.M., 2016. Dimensions of biodiversity in the Earth mycobiome. Nat. Rev. Microbiol. 14, 434-447.

Persson Vasaitis, R., Langstrom, B., Ohrn, P., Ihrmark, K., Stenlid, J., 2009. Fungi vectored by the bark beetle Ips typographus following hibernation under the bark of standing trees and in the forest litter. Microb. Ecol. 58, 651-659.

Poulin, R., 2007. Evolutionary Ecology of Parasites, second ed. Princeton University Press.

Poulin, R., Krasnov, B.R., Shenbrot, G.I., Mouillot, D., Khokhlova, I.S., 2006. Evolution of host specificity in fleas: is it directional and irreversible? Int. J. Parasitol. 36, 185-191.

Purahong, W., Wubet, T., Kruger, D., Buscot, F., 2018. Molecular evidence strongly supports deadwood-inhabiting fungi exhibiting unexpected tree species preferences in temperate forests. ISME J. 12, 289-295. https://doi.org/10.1038/ ismej.2017.177.

R Core Team, 2017. R development Core Team. Radiokhimiya: Lang. Environ. Stat. Comput. 55, 275-286.

Rabern Simmons, D., Wilhelm de Beer, Z., Huang, Y.-T., Bateman, C., Campbell, A.S., Dreaden, T.J., Li, Y., Ploetz, R.C., Black, A., Li, H.F., Chen, C.Y., Wingfield, M.J., Hulcr, J., 2016. New Raffaelea Species (Ophiostomatales) from the USA and Taiwan associated with Ambrosia Beetles and Plant Hosts. IMA Fungus 7, 265-273.

Reay, S., Thwaites, J., Farrell, R.L., Walsh, P.J., 2001. The role of the bark beetle, Hylastes ater (Coleoptera: scolytidae), as a sapstain fungi vector to Pinus radiata seedlings: a crisis for the New Zealand forestry industry? Integr. Pest Manag. Rev. 6, 283-291.

Romón, P., Zhou, X., Iturrondobeitia, J.C., Wingfield, M.J., Goldarazena, A., 2007. Ophiostoma species (Ascomycetes: Ophiostomatales) associated with bark beetles (Coleoptera: Scolytinae) colonizing Pinus radiata in northern Spain. Can. J. Microbiol. 53, 756-767.

Rudgers, J.A., Bell-Dereske, L., Crawford, K.M., Emery, S.M., 2015. Fungal symbiont effects on dune plant diversity depend on precipitation. J. Ecol. 103, 219-230.

Schmieder, R., Edwards, R., 2011. Quality control and preprocessing of metagenomic datasets. Bioinformatics 27, 863-864.

Silva, X., 2011. Studies on Fungi Associated with Tomicus Piniperda L. In Finland. MSc Thesis. University of Helsinki.

Sinclair, L., Osman, O.A., Bertilsson, S., Eiler, A., 2015. Microbial community composition and diversity via 16S rRNA gene amplicons: evaluating the illumina platform. PLoS One, 0116955.

Six, D.L., 2003. Bark beetle-fungus symbioses. In: Bourtzis, K., Miller, T. (Eds.), Insect Symbiosis. CRC Press, FL, USA, pp. 97-114.

Six, D.L., 2012. Ecological and evolutionary determinants of bark beetle - fungus symbioses. Insects 3, 339-366.

Skelton, J., Johnson, A.J., Jusino, M.A., Bateman, C.C., Li, Y., Hulcr, J., 2019. A selective fungal transport organ (mycangium) maintains coarse phylogenetic congruence between fungus-farming ambrosia beetles and their symbionts. Proc. R. Soc. B: Biol. Sci. 286 (1894). https://doi.org/10.1098/rspb.2018.2127.

Skelton, J., Jusino, M.A., Li, Y., Bateman, C., Thai, P.H., Wu, C., Lindner, D.L., Hulcr, J., 2018. Detecting symbioses in complex communities: the fungal symbionts of bark and ambrosia beetles within asian pines. Microb. Ecol. 76, 839-850.

Tedersoo, L., Bahram, M., Polme, S., Kõljalg, U., Yorou, N.S., Wijesundera, R., Villarreal Ruiz, L., Vasco-Palacios, A.M., Thu, P.Q., Suija, A., Smith, M.E., Sharp, C., Saluveer, E., Saitta, A., Rosas, M., Riit, T., Ratkowsky, D., Pritsch, K., Põldmaa, K., Piepenbring, M., Phosri, C., Peterson, M., Parts, K., Pärtel, K., Otsing, E., Nouhra, E., Njouonkou, A.L., Nilsson, R.H., Morgado, L.N., Mayor, J., May, T.W., Majuakim, L., Lodge, D.J., Lee, S.S., Larsson, K.H., Kohout, P., Hosaka, K., Hiiesalu, I., Henkel, T.W., Harend, H., Guo, L.D., Greslebin, A., Grelet, G., Geml, J., Gates, G., Dunstan, W., Dunk, C., Drenkhan, R., Dearnaley, J., De Kesel, A., Dang, T., Chen, X., Buegger, F., Brearley, F.Q., Bonito, G., Anslan, S., Abell, S., Abarenkov, K., 2014. Global diversity and geography of soil fungal. Science 346, 1052-1053.

Toju, H., 2015. High-throughput DNA barcoding for ecological network studies. Popul. Ecol. 57, 37-51.

Toju, H., Sato, H., Yamamoto, S., Kadowaki, K., Tanabe, A.S., Yazawa, S., Nishimura, O., Agata, K., 2013. How are plant and fungal communities linked to each other in belowground ecosystems? A massively parallel pyrosequencing analysis of the association specificity of root-associated fungi and their host plants. Ecol. Evol. 3, 3112-3124.

Webber, J., 2000. Insect vector behavior and the evolution of Dutch elm disease. In: Dunn, C. (Ed.), The Elms. Springer US, pp. 47-60.

Weiser, J., Wegensteiner, R., Handel, U., Zizka, Z., 2003. Infections with the ascomycete fungus Metschnikowia typographi sp.nov in the bark beetles Ips typographus and Ips amitinus (Coleoptera, Scolytidae). Folia Microbiol. 48, 611-618.

White, J.T., Bruns, T., Lee, S., Taylor, J., 1990. Amplification and direct sequencing of fungal ribosomal RNA genes for phylogenetics. In: Innis, M., Gelfand, D., Shinsky, J., White, T. (Eds.), PCR Protocols a Guide to Methods and Applications. Academic Press, San Diego, pp. 315-322.

Whittaker, J., 1984. Model interpretation from the additive elements of the likelihood function. Appl. Stat. 33, 52-65.

Winter, C., Matthews, B., Suttle, C.A., 2013. Effects of environmental variation and spatial distance on Bacteria, Archaea and viruses in sub-polar and arctic waters. 
ISME J. 7, 1507-1518.

Yamada, Y. Maeda, K. Mikata, K. 1994. The phylogenetic relationships of the hatshaped ascospore-forming, nitrate-assimilating Pichia species, formerly classified in the genus Hansenula, based on the partial sequences of 18S-ribosomal and 26S-ribosomal-rnas (Saccharomycetaceae). Biosci. Technol. Biochem. 58, $1245-1257$.

Yaman, M., Radek, R., 2008. Pathogens and parasites of adults of the great spruce bark beetle, Dendroctonus micans (Kugelann) (Coleoptera: Curculionidae,
Scolytinae) from Turkey. J. Pest. Sci. 81, 91-97.

Yamaoka, Y., Wingfield, M.J., Takahashi, I., Solheim, H., 1997. Ophiostomatoid fung associated with the spruce bark beetle Ips typographus $f$. aponicus in Japan. Mycol. Res. 101, 1215-1227.

Zumr, V., 1992. Dispersal of the spruce bark beetle Ips typographus (L) (Col, Scolytidae) in spruce woods. J. Appl. Entomol. 114, 348-352.

Zuur, A.F., Ieno, E.N., Walker, N.J., Saveliev, A.A., Smith, G.M., 2009. Mixed Effects Models and Extensions in Ecology with R. Springer, New York, New York, NY. 